\title{
Effect of divalent cations on the interaction of carboxylate self assembled monolayers
}

Rios-Carvajal, T.; Bovet, Nicolas; Bechgaard, K.; Stipp, Susan S. L.; Hassenkam, T.

Published in:

Langmuir

Link to article, DOI:

10.1021/acs.langmuir.9b02694

Publication date:

2019

Document Version

Peer reviewed version

Link back to DTU Orbit

Citation $(A P A)$ :

Rios-Carvajal, T., Bovet, N., Bechgaard, K., Stipp, S. S. L., \& Hassenkam, T. (2019). Effect of divalent cations on the interaction of carboxylate self assembled monolayers. Langmuir, 35(49), 16153-16163.

https://doi.org/10.1021/acs.langmuir.9b02694

\section{General rights}

Copyright and moral rights for the publications made accessible in the public portal are retained by the authors and/or other copyright owners and it is a condition of accessing publications that users recognise and abide by the legal requirements associated with these rights.

- Users may download and print one copy of any publication from the public portal for the purpose of private study or research.

- You may not further distribute the material or use it for any profit-making activity or commercial gain

- You may freely distribute the URL identifying the publication in the public portal 
Subscriber access provided by DTU Library

\title{
Interfaces: Adsorption, Reactions, Films, Forces, Measurement Techniques, Charge
}

\section{Transfer, Electrochemistry, Electrocatalysis, Energy Production and Storage}

\section{Effect of divalent cations on the interaction of carboxylate self assembled monolayers}

\author{
T. Rios-Carvajal, Nicolas Bovet, Klaus Bechgaard, Susan S.L. Stipp, and Tue Hassenkam \\ Langmuir, Just Accepted Manuscript • DOI: 10.1021/acs.langmuir.9b02694 • Publication Date (Web): 13 Nov 2019 \\ Downloaded from pubs.acs.org on November 18, 2019
}

\section{Just Accepted}

"Just Accepted" manuscripts have been peer-reviewed and accepted for publication. They are posted online prior to technical editing, formatting for publication and author proofing. The American Chemical Society provides "Just Accepted" as a service to the research community to expedite the dissemination of scientific material as soon as possible after acceptance. "Just Accepted" manuscripts appear in full in PDF format accompanied by an HTML abstract. "Just Accepted" manuscripts have been fully peer reviewed, but should not be considered the official version of record. They are citable by the Digital Object Identifier (DOI®). "Just Accepted" is an optional service offered to authors. Therefore, the "Just Accepted" Web site may not include all articles that will be published in the journal. After a manuscript is technically edited and formatted, it will be removed from the "Just Accepted" Web site and published as an ASAP article. Note that technical editing may introduce minor changes to the manuscript text and/or graphics which could affect content, and all legal disclaimers and ethical guidelines that apply to the journal pertain. ACS cannot be held responsible for errors or consequences arising from the use of information contained in these "Just Accepted" manuscripts. 


\title{
Effect of divalent cations on the interaction of
}

\section{carboxylate self assembled monolayers}

\author{
T. Rios-Carvajal1*, N. Bovet ${ }^{2}$, K. Bechgaardt, S.L.S. Stipp ${ }^{3}$, T. Hassenkam ${ }^{4}$ \\ ${ }^{1}$ Haldor Topsøe A/S, Kongens Lyngby, Denmark \\ 2Danish Hydrocarbon Research and Technology Center (DHRTC), Technical University of \\ Denmark (DTU), Kongens Lyngby, Denmark \\ ${ }^{3}$ Department of Physics, Danish Technical University (DTU), Kongens Lyngby, Denmark \\ ${ }^{4}$ Nano-Science Center, Department of Chemistry, University of Copenhagen, Denmark
}

Keywords: Chemical force mapping, adhesion force, specific ion effects, ion bridging, malonate complexation.

* corresponding author, trca@topsoe.com

+ deceased 
prepared for Langmuir

\begin{abstract}
Interactions between organic molecules in aqueous environments, whether in the fluid phase or adsorbed on solids, are often affected by the cations present in the solution. We investigated, at nanometre scale, how surface carboxylate interactions are influenced by dissolved divalent cations: $\mathrm{Mg}^{2+}, \mathrm{Ca}^{2+}, \mathrm{Sr}^{2+}$ and $\mathrm{Ba}^{2+}$. Self assembled monolayer (SAM) surfaces with exposed terminations of alkyl, $-\mathrm{CH}_{3}$, carboxylate, - $\mathrm{COO}^{-}$or dicarboxylate, DiCOO-, were deposited on gold coated tips and substrates. We used atomic force microscopy (AFM), in chemical force mapping (CFM) mode, to measure adhesion forces between various combinations of SAMs on the tip and substrate, in solutions of $0.5 \mathrm{M}$ $\mathrm{NaCl}$, that contained $0.012 \mathrm{M}$ of one of the divalent cations.
\end{abstract}

The type of cation, the number of carboxyl groups that interact and their structure on the SAM influenced adhesion between the surfaces. The effect of the reference solution, which only contains $\mathrm{Na}^{+}$cations, on adhesion force was mainly attributed to van der Waals and hydrophobic forces, explaining lower force in systems that are more hydrophilic, i.e., - $\mathrm{COO}^{-} \mathrm{COO}^{-}$, and higher force for more hydrophobic systems. For charged surfaces, i.e., -COO- and - $\mathrm{DiCOO}^{-}$, in divalent cation solutions, results were consistent with ion bridging. The inclusion of a hydrophobic surface, i.e., the $-\mathrm{CH}_{3}-\mathrm{COO}^{-}$or $-\mathrm{CH}_{3}-\mathrm{DiCOO}^{-}$system, decreased the possibility for strong cation bridging with the charged surface, resulting in 
lower adhesion. For systems including -COO', the adhesion force series followed the inverse cation hydrated radius trend $\left(\mathrm{Na}^{+} \sim \mathrm{Mg}^{2+}<\mathrm{Sr}^{2+}<\mathrm{Ca}^{2+}<\mathrm{Ba}^{2+}\right)$ whereas - DiCOO- was responsible for lower adhesion force and modified trends, depending on the corresponding surface in the system. Differences in force magnitude between the monolayers were correlated with lower charge availability on the - DiCOO- surface as a result of fewer active sites, probably because of the tendency of exposed malonate surface groups to interact between them, as well as high rigidity, resulting from the molecule structure. The characteristic response of the -DiCOO- surface in solutions of $\mathrm{Sr}^{2+}$ and $\mathrm{Ca}^{2+}$ was correlated with possible malonate complexation modes. Comparison with previous studies suggested that the strong response of a -DiCOO- surface to $\mathrm{Sr}^{2+}$ resulted from bidentate chelation, whereas $\mathrm{Ca}^{2+}$ response was attributed to alpha mode association to malonate.

\section{INTRODUCTION}

Interactions between organic molecules and metal ions in aqueous environments play a key role for innumerable chemical and biochemical processes. Although the first description of selective interactions between simple ions and organic molecules dates back to Hofmeister's research in 1888, published work mainly explores the effects of those interactions on properties such as surface tension, ${ }^{1,2}$ solubility of hydrocarbons, ${ }^{3,4}$ colloid stability, $^{5-7}$ enzymatic activity ${ }^{8}$ and clay swelling. ${ }^{9,10}$ The underlying reasons for those 
effects have rarely been investigated. A physical phenomenon that is often used to explain many of the observed specific ion effects associated with aqueous interfaces is pairing or complexing between simple ions and charged organic functionalised surfaces. Ion-surface interactions have been studied experimentally using contact angle measurements, ${ }^{11-13}$ adsorption of ions on substrates ${ }^{14-17}$ and most relevant for our case, direct measurement of the forces between two interacting bodies in electrolyte solution, either using the surface force apparatus (SFA) ${ }^{18-21}$ or atomic force microscopy (AFM) ${ }^{22-24}$.

In our research group, we have studied adhesion behavior between various organic functional groups (polar, nonpolar, aromatic) and natural surfaces, in solutions containing various ions, $4,24-27$ by using a modification of AFM, called chemical force microscopy (CFM). ${ }^{28}$ Usually CFM forces are compared with theoretical approximations for the forces involved in ion-surface interactions, that are commonly described as a combination of van der Waals interactions $\left(\mathrm{F}_{\mathrm{vd}}\right)$, electrostatic forces $\left(\mathrm{F}_{\mathrm{EDL}}\right)$ and hydration interactions $\left(\mathrm{F}_{\mathrm{HI}}\right)^{29,30}$ Observations show that depending on the organic group exposed at the surface, the contribution of each of the forces, i.e. $F_{\mathrm{VdW}}, \mathrm{F}_{\mathrm{EDL}}$ and $\mathrm{F}_{\mathrm{HI}}$ is different. For example, Rimmen et al. ${ }^{24}$ proved that the adhesion force between phenoxy SAMs is mostly a result of $F_{v d W}$ between the surfaces whereas the adhesion force when two methyl SAMs interact is mainly driven by the hydrophobic force. ${ }^{31}$

In a previous AFM study 32 where we explored the effect of alkali metal cations on adhesion between self assembled monolayer (SAM) surfaces with a deprotonated 
carboxyl (-COO-), the measured adhesion forces could not be described by the sum of the contributing forces, implying that there were additional forces involved in the interaction. Results of that investigation suggest that specific ion effects and increased adhesion forces for interaction of negatively charged organic molecules (i.e. deprotonated carboxylic acids, $-\mathrm{COO}^{-}$), in solutions of positively charged metal cations (mainly $\mathrm{Mg}^{2+}$, $\left.\mathrm{Na}^{+}, \mathrm{Ca}^{2+}\right)$, can be explained by ion bridging. An ion bridge results from attractive interactions where two, like charged sites are linked by an oppositely charged ion, by Coulomb interaction. ${ }^{33}$ Several studies have reported about how the size and hydration of the cation and the charge on the surfaces affect ion bridge strength. ${ }^{34-36}$ However, the details about how organic molecules influence the interaction, for example through their molecular structure and carboxyl group bonding, i.e. atom distances and angles between the active groups, and the molecules themselves on the SAM surface, are not fully understood. ${ }^{10,37}$

We investigated the interaction, at nanometre scale, of two different carboxyl terminations in solutions containing one of four divalent, alkali earth cations $\left(\mathrm{Mg}^{2+}, \mathrm{Ca}^{2+}\right.$, $\mathrm{Sr}^{2+}$ and $\mathrm{Ba}^{2+}$. We used AFM in CFM mode to explore the interaction between the SAMs on the tip and the surface that were both functionalised with organic molecules. We created systems from three different functional group terminations: $-\mathrm{CH}_{3},-\mathrm{COO}^{-}$and DiCOO- By comparing the adhesion force between systems that contain - $\mathrm{COO}^{-}$or DiCOO- surfaces, we evaluated the effect of surface charge density and chemical structure. 
We also examined how adhesion force between the various SAMs was affected by the presence of the reference solution $(\mathrm{NaCl})$ and divalent ions, how the chemical conformation of a system could lead to preferential interaction by some cations, and the consistency of interaction with ion induced bridging.

\section{METHODS}

\section{Synthesis of the dicarboxylic acid, alkanethiol}

SAMs are composed of three main parts: the end or base group, that binds to the supporting substrate; the chain or spacer, that is usually an alkane chain that gives length and separates the exposed head group from the end bound to the supporting substrate, usually bearing a thin layer of gold, and the head group or the termination, that is exposed in the solution and that defines the functionality of the SAM surface. Thiol is widely used as end group for SAM formation to gold coated surfaces ${ }^{38}$ because the $S$ of the thiol binds strongly and dependably to $\mathrm{Au}$, exposing the head group. To produce a - $\mathrm{COO}^{-} \mathrm{SAM}$, we used commercially available 11-mercaptoundecanoic acid (99\%) from Sigma Aldrich. The molecule required for forming an analogous -DiCOO- SAM surface: 2-(10-mercaptodecyl)-malonic acid (Molecule 2, Scheme 1) was not commercially available so we synthesized it, following a modification of the reported pathway of Simard et al. ${ }^{39}$.

The synthesis was performed in two steps (Scheme 1), to obtain Molecule 1, Diethyl 2(10-bromo-decyl)-malonic acid and then to deprotect the ester to obtain the carboxylic 
acid in 2-(10-mercapto-decyl)-malonic acid (Molecule 2). The detailed route is shown in Scheme 1.

Scheme 1. Synthetic route for producing the -DiCOO- thiol precursor, 2-(10mercaptodecyl)malonic acid (2) modified from Simard et.al. ${ }^{39}$.

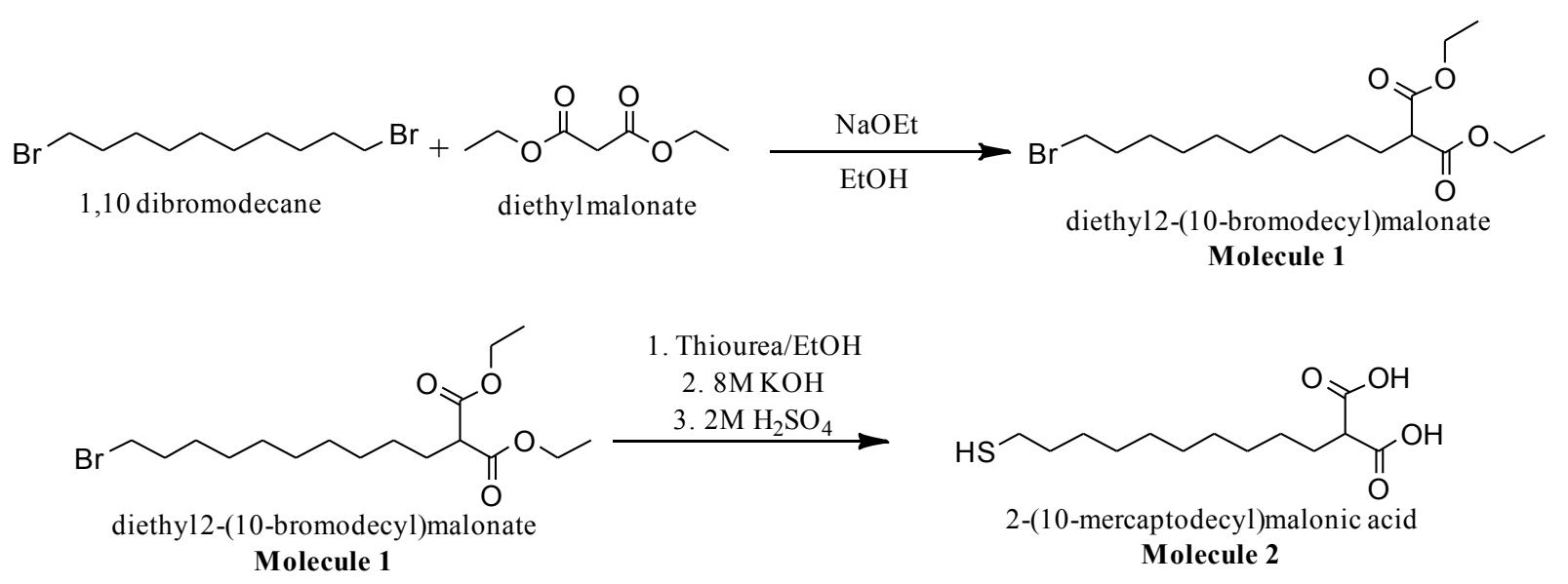

Diethyl 2-(10-bromo-decyl)-malonate (1)

Sodium ethoxide ( $820 \mathrm{mg} 12.0 \mathrm{mmol}$ ), NaOEt, was added to a homogeneous solution of diethyl malonate $(1.78 \mathrm{~g}, 11.1 \mathrm{mmol})$ in absolute ethanol. Then an ethanolic solution of 1.10 dibromodecane $(5 \mathrm{~g}, 16.7 \mathrm{mmol})$ was added slowly and the mixture kept stirring for 36 hours. The solution was poured over ice and the organic layer was separated and washed three times with hexane to remove the excess of 1,10 -dibromodecane. The organic layer was dried over $\mathrm{MgSO}_{4}$ and reduced in vacuum. The resulting product was purified by dry column vacuum chromatography with a gradient starting with pure hexane to pure chloroform, to give a clear oil (yield $60 \%){ }^{1} \mathrm{H} \mathrm{NMR}\left(500 \mathrm{MHz}, \mathrm{CDCl}_{3}\right)$. Details are 
presented in Supporting Information ( ${ }^{1} \mathrm{H}$ NMR spectrum, Figure S1. $\delta: 4.22(\mathrm{q}, 4 \mathrm{H}), 3.42(\mathrm{t}$, 2H), $3.33(\mathrm{t}, 1 \mathrm{H}), 1.88(\mathrm{~m}, 4 \mathrm{H}), 1.28(\mathrm{~m}, 2 \mathrm{H}) .{ }^{13} \mathrm{C} \mathrm{NMR}$ spectrum $\left(126 \mathrm{MHz}, \mathrm{CDCl}_{3}\right)$, Figure S2, $\delta: 169.76,61.38,52.21,34.16,32.96,29.49,29.38,29.32,28.86,28.29,27.95,27.43$, 24.03, 14.23. HRMS-MALDI TOF $[\mathrm{M}+\mathrm{H}]^{+}$, Figure S3: $\mathrm{m} / \mathrm{z}$ 377.15). 2-(10-mercapto-decyl)-malonic acid (2)

An ethanolic solution of thiourea $(1.2 \mathrm{~g}, 15.7 \mathrm{mmol})$ and Molecule $1(2.9 \mathrm{~g}, 7.6 \mathrm{mmol})$ was prepared and allowed to reflux overnight. The mixture was reduced in vacuum, an 8 $\mathrm{M}$ solution of $\mathrm{KOH}$ was added and the resulting mix was allowed to react for 4 hours. The organic product was extracted with acetate and acidified with a $2.5 \mathrm{M} \mathrm{H}_{2} \mathrm{SO}_{4}$ solution, which formed a white precipitate that could be separated by filtration. The solid was washed several times with water and recrystallised in acetone to give Molecule 2 as a white solid. The procedure is shown in Scheme 2 and the spectra are shown in Supporting Information ( ${ }^{1} \mathrm{H} \mathrm{NMR,} 500 \mathrm{MHz}, \mathrm{CDCl}_{3}$, Figure S4, $\delta: 3.45(\mathrm{t}, 1 \mathrm{H}), 2.69(\mathrm{q}, 2 \mathrm{H}), 1.95(\mathrm{q}, 2 \mathrm{H})$, $1.59(\mathrm{~m}, 2 \mathrm{H}), 1.26(\mathrm{~m}, 14 \mathrm{H}) ;{ }^{13} \mathrm{C} \mathrm{NMR}, 500 \mathrm{MHz}, \mathrm{CDCl}_{3}$, Figure S5, 8: 34.16, 29.53, 29.50, 29.32, 28.39, 27.26, 24.81; HRMS-MALDI TOF $[\mathrm{M}+\mathrm{H}]^{+}$, Figure S6, m/z 277.15.

\section{Preparation of the SAM surfaces}

Prior to each of the AFM experiments, we functionalised the interacting surfaces. We used AFM gold Biolevers (purchased from Olympus, Reference BL-RC-150VB) and ultraflat $1 \mathrm{~cm}^{2}$ gold surfaces for SAM formation. The gold coated, silica substrates of $\sim 1 \mathrm{~cm}^{2}$ were made using the stripping approach, ${ }^{40}$ where silicon wafer squares of the desired size were 
glued to the gold side of a gold coated silicon wafer ( $50 \mathrm{~nm}$ gold coverage, Platypus Technologies) ${ }^{41}$ using EPOTek 353ND. The glue was cured by heating the sandwich (Siglue-Au-Si) at $120^{\circ} \mathrm{C}$, in air for $30 \mathrm{~min}$. After cooling, the squares could be pulled away, stripping the gold from the wafer, producing a fresh, clean, flat, gold surface that was used immediately for SAM formation.

The SAM was formed by reacting thiol molecules with a gold coated AFM tip or sample surface. AFM gold biolevers (Olympus BL-RC-150VB) and freshly stripped gold substrates were cleaned on a UV-ozone procleaner (Bioforce Nanoscience) for 20 minutes and then immersed in a 4-5 $\mathrm{mM}$ ethanol solution (absolute ethanol $\geq 99.8 \%$ semiconductor grade PURANAL ${ }^{\text {TM }}$ ) of the desired thiol: 1-uncanethiol (98\%, Sigma Aldrich), for a $-\mathrm{CH}_{3}$ functionalised SAM substrate, 11-mercaptoundecanoic acid (99\%, Sigma Aldrich), for a COO- SAM substrate and synthesized 2-(10-mercapto-decyl)-malonic acid for a -DiCOOSAM substrate. After 24 hours, when a monolayer was assumed to have been formed, ${ }^{42}$ and just prior to use in CFM measurements, the tip and sample were removed from the solution and rinsed in ethanol (absolute ethanol $\geq 99.8 \%$ semiconductor grade PURANAL ${ }^{\text {TM }}$ ) for 30 minutes to remove the unbound thiol molecules. The composition of the SAMs were confirmed by X-ray photoelectron spectroscopy.

\section{Solution preparation}

All solutions were made from a stock solution of $0.5 \mathrm{M} \mathrm{NaCl}$ by adding a divalent cation chloride salt (one of: $\mathrm{MgCl}_{2}, \mathrm{CaCl}_{2}, \mathrm{SrCl}_{2}$ or $\mathrm{BaCl}_{2}$ ) to produce $12 \mathrm{mM} \mathrm{Me}^{2+}$ concentration. 
Prior to use, all solutions were equilibrated with air and adjusted to 8.2-8.3 from $\mathrm{pH} 5.5$ with $0.2 \mathrm{M} \mathrm{NaOH}$. The concentration of the solutions was chosen to be roughly on the order of magnitude of these ions in sea water, ${ }^{43}$ therefore in the range of a relevant environment for interaction of organic compounds. We used ultrapure deionized water (Milli-Q, resistivity $>18.2 \mathrm{M} \Omega \cdot \mathrm{cm}$ ) and chemical compounds of reagent grade or better, supplied by Sigma-Aldrich.

\section{Chemical force mapping (CFM)}

All CFM experiments were made using an Asylum Research MFP-3D atomic force microscope. All tips were Olympus biolever AFM probes, functionalised using the method described above. In each experiment, the deflection sensitivity of each tip was determined. For this work we used only soft cantilevers with a nominal spring constant of $6 \mathrm{pN} / \mathrm{nm}$.

A chemical force map (Figure 1a) was collected from $30 \times 30$ data points over an area of $5 \times 5 \mathrm{~mm}^{2}$, following the procedure reported elsewhere. ${ }^{24,44,45}$ The surface was first scanned by AFM to check that the portion of the SAM to be tested was flat and uniform, reducing the probabilities of finding unbound leftover molecules at the surface from the SAM preparation processor inhomogeneities due to a scratch on the Au underlying surface. Each pixel in the force map represents a force curve (Figure 1, c-e) that records how the tip moved toward the surface, came into contact and stopped when the surface resisted with a predetermined force $(500 \mathrm{pN})$. The tip was then retracted from the surface and as it moved away, adhesion between tip and sample caused the cantilever to deflect. 
At some displacement, the tip snapped free. The maximum force just before release was the adhesion force. From the 900 force curves that were recorded over each surface for each scan, a force map was generated. The distribution of the 900 force curves follows a Gaussian distribution described in Figure 1b. The surface was assumed to be homogenous so from the force maps, we could determine the average adhesion $\left(F_{A D}\right)$ over the whole map for that set of conditions.

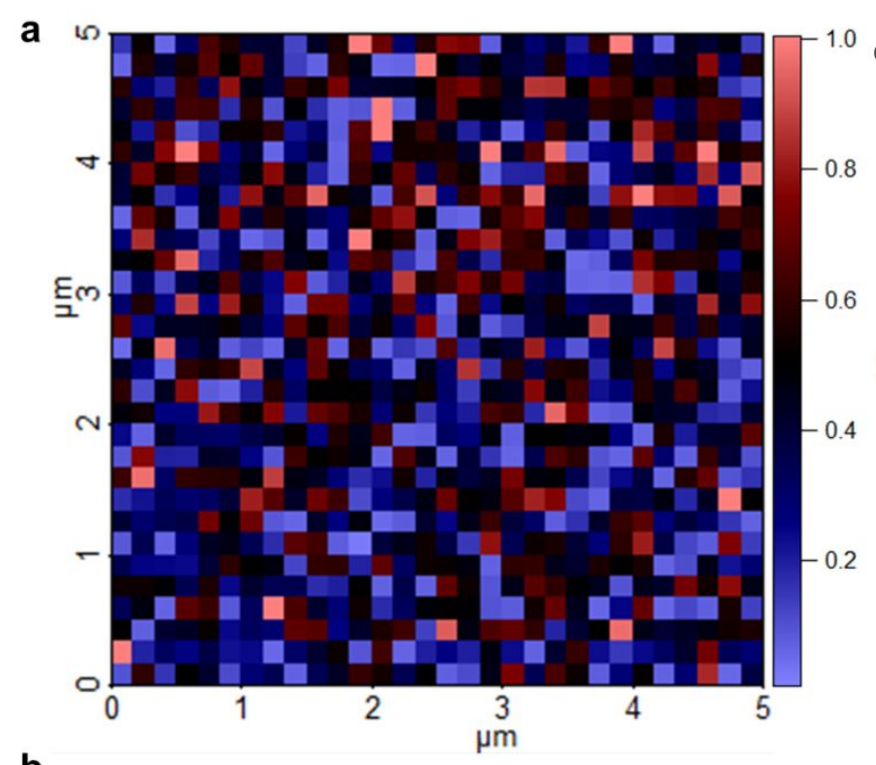

b
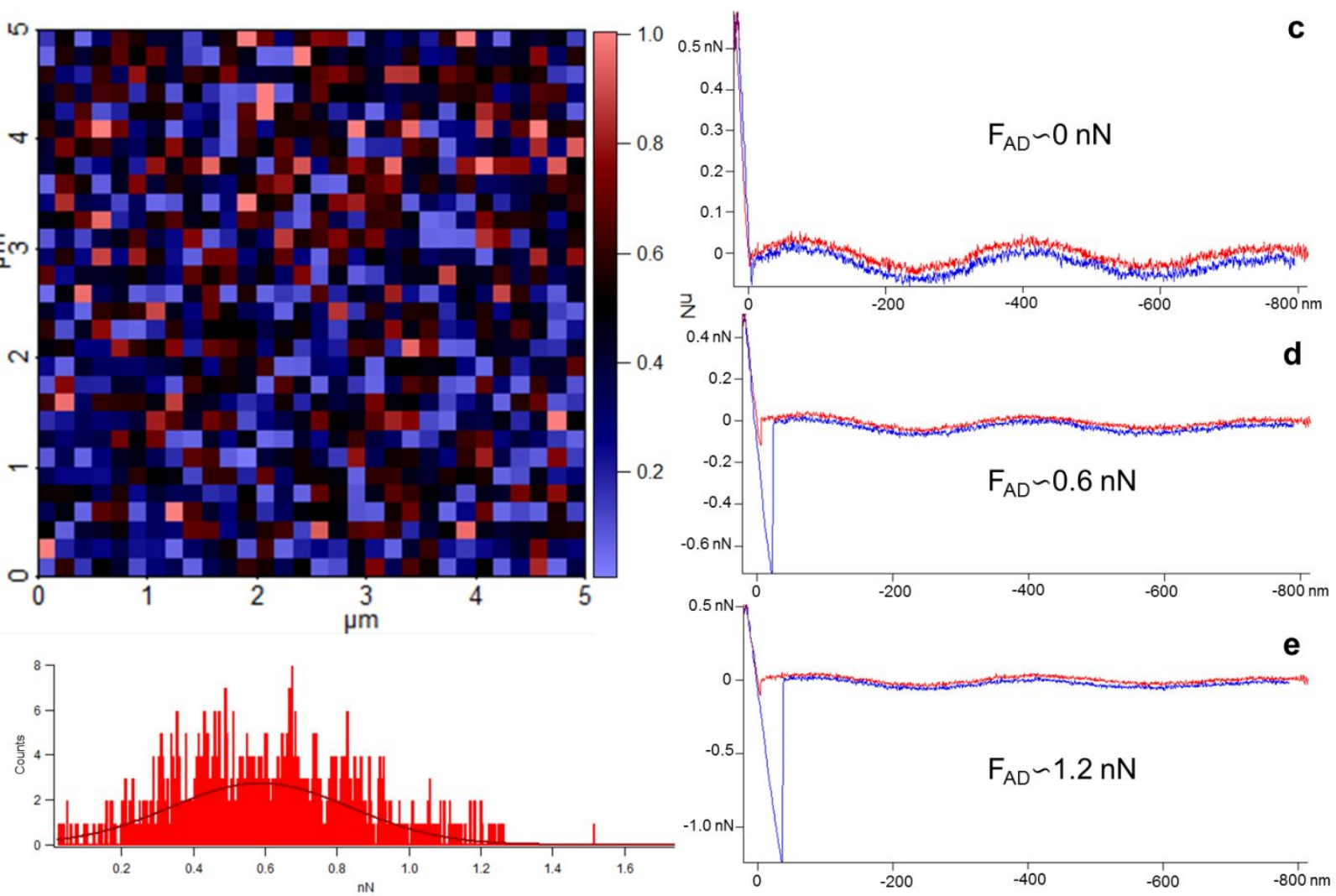

Figure 1. Typical AFM force data from a CFM experiment in $\mathrm{CaCl}_{2}$ solution over a $5 \mu \mathrm{m} x$ $5 \mu \mathrm{m}$ area of a surface. a) Force map derived from 900 individual force curves, where each pixel represents the adhesion force extracted from single force curves. An average adhesion force $\left(\mathrm{F}_{\mathrm{AD}}\right)$ was extracted for each map. b) Distribution of the adhesion forces 
extracted from the 900 force curves to obtain the force map in a. Three force curves (c-e) show representative force curves for the color code use in the force map: c) pale blue, lowest adhesion force $\backsim 0 \mathrm{nN}$; d) purple-black, average adhesion force $\backsim 0.6 \mathrm{nN}$; e) red, highest adhesion force $>1.0 \mathrm{nN}$.

We tested 5 systems (Table 1 ). We include results for the sixth system, $-\mathrm{CH}_{3}-\mathrm{CH}_{3}$, that were presented in an earlier work, to facilitate comparison. ${ }^{32}$ We named the systems by the active group on the tip, followed by the active group on the surface, i.e: $\mathrm{CH}_{3}-\mathrm{DiCOO}^{-}$ represents the system where the tip is a methyl SAM and the substrate is a -DiCOO- SAM. At the $\mathrm{pH}$ and solution composition of our experiments, the carboxyl groups at SAM surfaces are expected to be mostly (i.e., $80-90 \%$ ) deprotonated ${ }^{32,46}$ so surfaces are named in their deprotonated form, i.e., $-\mathrm{COO}^{-}$rather than $-\mathrm{COOH}$. In a set of test experiments, we verified that the response was the same in the asymmetric system, whether it was the tip or the surface that was hydrophobic. In a previous study, ${ }^{32}$ we demonstrated that the interaction between two hydrophobic surfaces $\left(\mathrm{CH}_{3}-\mathrm{CH}_{3}\right)$, under the same experimental conditions that were used here, did not induce any specific ion response (Figure 2). Therefore, we used $-\mathrm{CH}_{3}-\mathrm{CH}_{3}$ SAMs as the standard for comparison of results from experiments where tip or substrate or both were charged. ${ }^{31,32}$

No two tips or surfaces are ever identical in size, shape or functional molecule coverage so to enable comparison of results from various solutions, we used the same tip and 
substrate for a series of solutions, investigated within one experiment. In each experiment, tip and surface were submerged in a fluid cell that contained $\sim 3 \mathrm{~mL}$ of solution. Each experiment began using the reference solution $(0.5 \mathrm{M} \mathrm{NaCl})$. After recording at least 3 maps, the reference solution was exchanged by extracting $\sim 2 \mathrm{~mL}$ from the liquid cell and then injecting $\sim 2 \mathrm{~mL}$ of the new divalent ion solution. We repeated the extraction procedure 4 times before the next set of adhesion data was taken, to ensure that $99.6 \%$ of the previous solution was replaced. Three new maps were recorded, then the solution was changed back to the reference solution, to test measurement reproducibility and to check for extended effects of cation exchange. This procedure was repeated until all divalent cation solutions were tested, using the same tip and sample and scanning over the same $5 \times 5 \mu m^{2}$ area of surface. To ensure that the ion effect that we observed was not affected by the previous cation solution, every set of surfaces was observed at least 4 times, with changed order of cations.

\section{X-ray photoelectron spectroscopy (XPS)}

The chemical state and the element composition of SAM surfaces were determined with XPS (Kratos Axis UltraDLD), using monochromatised Al Ka (hu=1486.6 eV, power $150 \mathrm{~W}$ ) as the excitation source. CasaXPS software was used to analyse the data and background was corrected using a Shirley fit. All the spectra were calibrated to the carbon Au $4 \mathrm{f}$ peak at $84 \mathrm{eV}$. Uncertainty in XPS binding energy is about $0.1 \mathrm{eV}$. Uncertainty in the atom percent, determined from XPS data, is on the order of $5-10 \%$. 


\section{RESULTS AND DISCUSSION}

Figure 2 presents a summary of the average adhesion force $\left(F_{A D}\right)$ obtained for the five surface systems evaluated in this work. Each circle represents the arithmetic mean of the three force maps resulting from the interaction of a specific system in a determined divalent ion solution. Data from a previous study, ${ }^{32}$ where $\mathrm{CH}_{3}-\mathrm{CH}_{3}$ behaviour was evaluated under the same conditions (ion concentration, $\mathrm{pH}$ ), are included for comparison.

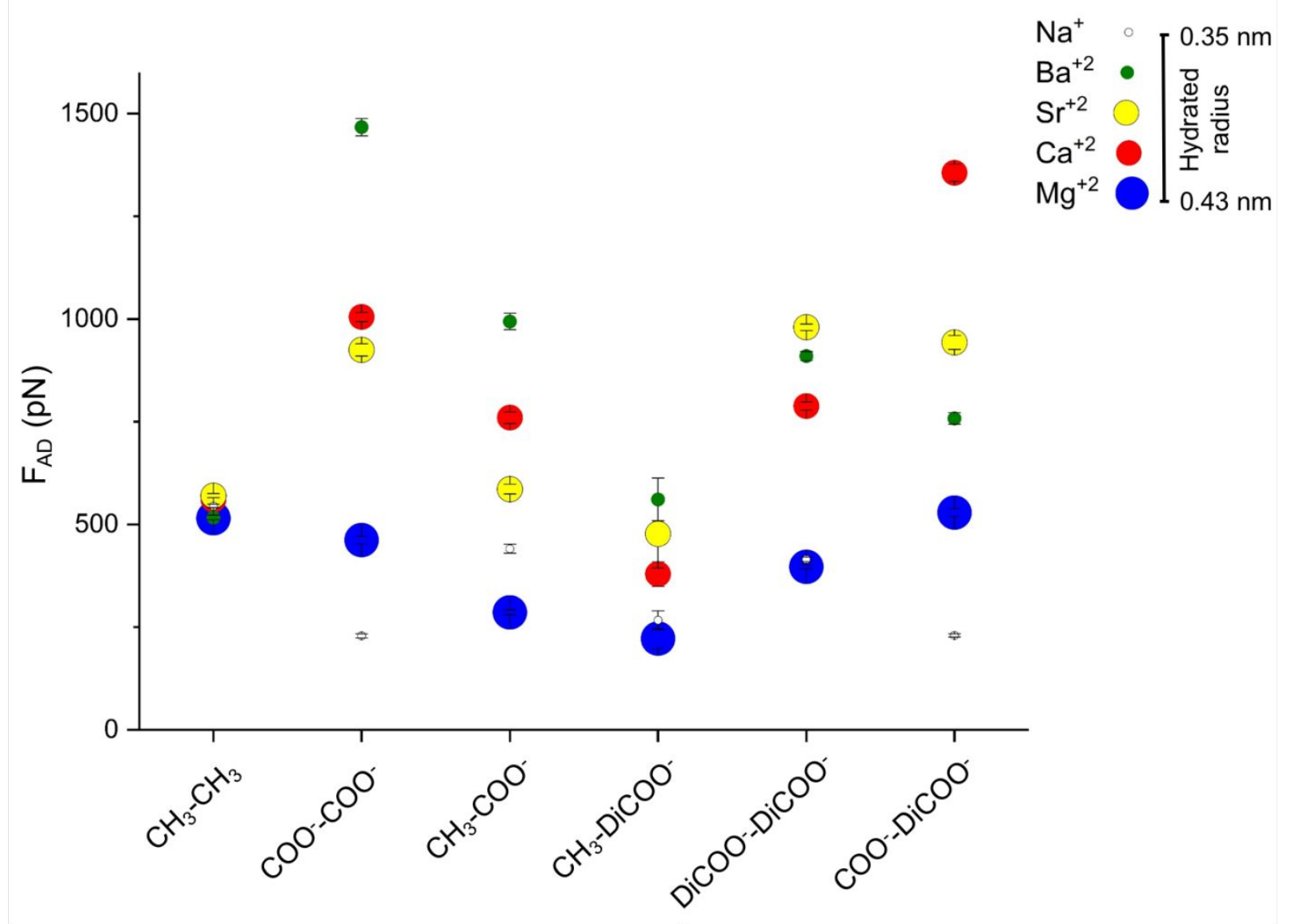


Figure 2. Average adhesion force measured for the various tip-substrate interactions during exposure to divalent cation solutions. The interaction systems are named by the SAM head group present on the tip and on the substrate, i.e., the second set of data was from the system with a $\mathrm{CH}_{3}$ tip probing a $-\mathrm{COO}^{-}$substrate. $\mathrm{CH}_{3}-\mathrm{CH}_{3}$ data from a previous study ${ }^{32}$ is also included for comparison. Each circle represents the average adhesion from 3 force maps ( 900 force curves each) and the range in force over all of the maps for each cation is represented by the standard error, as black bars.

As observed in Figure 2, the $\mathrm{CH}_{3}-\mathrm{CH}_{3}$ system is the only one that does not show ion specific effects on the adhesion force: $F_{A D}$ remains constant regardless of the cation present in the solution. For all systems, $\mathrm{Mg}^{2+}$ was the ion that caused the least effect on the adhesion force. The $\mathrm{Ba}^{2+}$ solution increased the adhesion force the most in the $\mathrm{CH}_{3}$ $\mathrm{COO}^{-}, \mathrm{COO}^{-} \mathrm{COO}^{-}$and $\mathrm{CH}_{3}-\mathrm{DiCOO}^{-}$systems, whereas $\mathrm{Ca}^{2+}$ provokes the highest increase

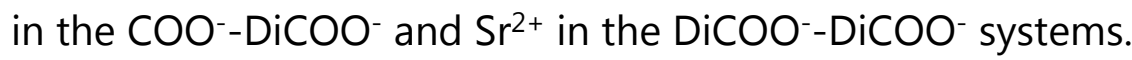

Table 1 summarises the average adhesion force $\left(\mathrm{F}_{\mathrm{AD}}\right)$ and provides data for comparing the different systems and ions: ionic radius, hydrated radius ${ }^{30,47,48}$ and the adhesion force difference $\left(\Delta \mathrm{F}_{\mathrm{AD}}\right)$, which is defined as:

$$
\Delta \mathrm{F}_{\mathrm{AD}}=\mathrm{F}_{\mathrm{ADCation}}-\mathrm{F}_{\mathrm{ADReference} \mathrm{solution}} \text { (1) }
$$

$\Delta \mathrm{F}_{\mathrm{AD}}$ quantifies the extent of adhesion that each cation contributes to the interacting system compared with the reference solution. Positive $\Delta \mathrm{F}_{A D}$ means an increase in the 
adhesion force. To facilitate comparison with other techniques, i.e. SFA, the average adhesion force normalized by contact radius, $F / R$, is also depicted.

Table 1. Summary of all adhesion force data (used to produce Figure 2), ionic ${ }^{49}$ and hydrated Radii. 30,48

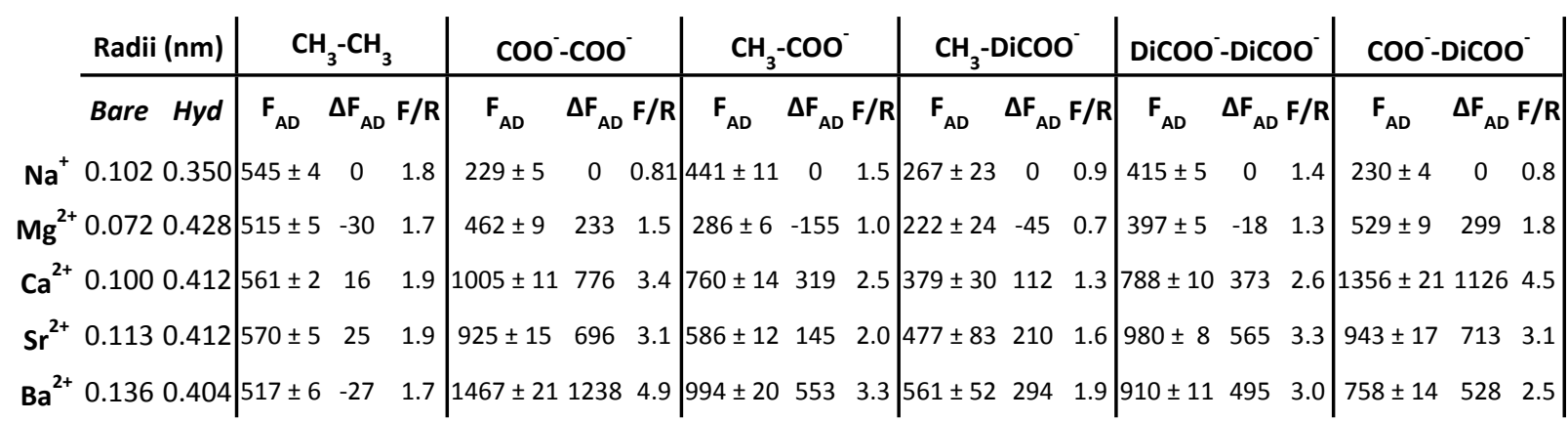

${ }^{a} \mathrm{~F}_{\mathrm{AD}}$ and $\Delta \mathrm{F}_{\mathrm{AD}}$ are in $\mathrm{pN}$ and $\mathrm{F} / \mathrm{R}$ is in $\mathrm{mN} / \mathrm{m}$

In contrast to the lack of specific ion response on the $\mathrm{CH}_{3}-\mathrm{CH}_{3}$ system, which has previously been reported by several authors, $31,32,50$ the extent of interaction between two carboxyl surfaces (COO--COO-) depended on the cation in the solution. In the reference solution, symmetric $\mathrm{COO}^{-} \mathrm{COO}^{-}$interaction resulted in adhesion force of $229 \pm 5 \mathrm{pN}$, which is the lowest adhesion force recorded for this system. In the $0.12 \mathrm{mM} \mathrm{Ba}^{2+}$ solution, the adhesion force was the highest $(1467 \pm 21 \mathrm{pN})$ observed in any of the systems. Solutions containing $\mathrm{Ca}^{2+}$ and $\mathrm{Sr}^{2+}$ resulted in similar adhesion forces $(1005 \pm 11 \mathrm{pN}$ and $925 \pm 15 \mathrm{pN})$ whereas in $\mathrm{Mg}^{2+}$ solutions, adhesion was lower, $(462 \pm 11 \mathrm{pN})$.

These measurements agree with results of previous experiments that were made under similar conditions with SAM surfaces terminated with hydrophobic and hydrophilic molecules. ${ }^{32}$ When the solution contained only $\mathrm{Na}^{+}$and $\mathrm{Cl}^{-}$, adhesion force was lower for 
the acidic system, i.e. the hydrophilic, COO--COO- system $(229 \pm 5 \mathrm{pN})$, than for the nonpolar, i.e. hydrophobic, $\mathrm{CH}_{3}-\mathrm{CH}_{3}$, system (545 $\pm 4 \mathrm{pN}$ ). The interaction between the two surfaces can be roughly described by an approximation of the expected contributing forces, i.e. electric double layer $\left(\mathrm{F}_{\mathrm{EDL}}\right)$, van der Waals $\left(\mathrm{F}_{\mathrm{vdW}}\right)$ and hydration $\left(\mathrm{F}_{\mathrm{HI}}\right)$ forces. For the $\mathrm{CH}_{3}-\mathrm{CH}_{3}$ system, adhesion force was dominated by the hydrophobic interaction, assuming small or no surface charge $\left(\mathrm{F}_{\mathrm{vdw}} \sim 100 \mathrm{pN} ; \mathrm{F}_{\mathrm{HI}} \sim 550 \mathrm{pN}\right){ }^{32} \mathrm{~A}$ similar result was obtained by Rimmen et al., ${ }^{24}$ who measured adhesion force between benzene SAMs during exposure to cations: $\mathrm{Na}^{+}, \mathrm{K}^{+}, \mathrm{Mg}^{2+}$ and $\mathrm{Ca}^{2+}$. Adhesion force remained relatively constant $(\sim 900 \mathrm{pN})$ in the various solutions. Force was attributed mainly to $\mathrm{F}_{\mathrm{vdW}}$ and $\mathrm{F}_{\mathrm{HI}}$. This is consistent with the lower adhesion for the more hydrophilic surfaces in the reference solution, which contains only $\mathrm{Na}^{+}$cations, suggesting that $\mathrm{Na}^{+}$plays a minor role in ion bridging. Thus, in the reference solution, adhesion can be mainly attributed to direct surface interactions through van der Waals and hydrophobic forces, which explains lower forces in systems that are more hydrophilic, i.e. $\mathrm{COO}^{-}-\mathrm{COO}^{-}$, and higher forces for more hydrophobic systems.

For divalent cation solutions, the correlation between ion bridge theory and the data recorded by CFM for the $\mathrm{COO}^{-} \mathrm{COO}^{-}$system was demonstrated. ${ }^{32}$ An approximation for the ion bridge contribution was made by an initial estimate of the number of carboxylate groups available for interaction in the $\mathrm{COO}^{-} \mathrm{COO}^{-}$system. To do this, we first approximated the effective area of interaction for our CFM experiment, using Derjaguin- 
Muller-Toporov (DMT) ${ }^{51}$ and Johnson-Kendall-Roberts (JKR) ${ }^{52}$ models. The estimation was based on the tip radius. Therefore, small variations could affect the area of interaction. According to the factory specifications, ${ }^{53}$ for the cantilevers used for this work (Olympus biolever RC150VB-HW, radius $30 \pm 2 \mathrm{~nm}$ ), expected tip radius variation is less than $10 \%$. Thus the estimated effective area from DMT and JFK, 32 could range from 3 to $6 \mathrm{~nm}^{2}$. By using the reported surface coverage of carboxyl SAMs ( 5 groups per $\left.\mathrm{nm}^{2}\right)^{54}$, we estimated the number of accessible molecules to range between 15 and 30, of which $\sim 90 \%$ were deprotonated. ${ }^{32,46}$ This means that 12 to $27-$ COO$^{-}$sites were deprotonated. ${ }^{32}$ We can approximate the overall force, if all of these form a bridge, as the sum $\left(F_{\text {Csum }}\right)$ of the Coulombic force $\left(F_{C}\right)$ from each bridge. Assuming that the ion stays fixed to one surface, $F_{C}$ would represent the force required for breaking an ion bridge from one side of the interaction. Using the $\mathrm{Me}^{2+}$ hydrated radius as the distance between the deprotonated carboxyl site on the surface and the tip, we can estimate the force of a single ion bridge:

$$
\mathrm{F}_{\mathrm{C}}=\frac{\mathrm{q}_{1} \mathrm{q}_{2}}{4 \pi \varepsilon_{0} \in \mathrm{D}^{2}},(2)
$$

where $q_{1}$ represents the charge of $-\mathrm{COO}^{-}$and $\mathrm{q}_{2}$, the charge of the cation. $\varepsilon_{0}$ represents the dielectric permittivity of the vacuum, $\varepsilon$, the relative permittivity of the solution and $D$, the distance of the interaction $(\mathrm{D}=1.4 \mathrm{~nm})^{32}$. This gives an $\mathrm{F}_{\mathrm{C}_{1}}$ for each interacting system, of 32 to $36 \mathrm{pN}$. Consequently, the overall adhesion force would be $\mathrm{F}_{\text {csum }}=384$ to $977 \mathrm{pN}$. The upper limit of the range is on the same order of magnitude as the CFM measurements 
for the COO-COO- system (Table 1: $925 \pm 15$ pN for $\mathrm{Sr}^{2+}, 1005 \pm 11 \mathrm{pN}$ for $\mathrm{Ca}^{2+}$ and 1467 \pm 21 for $\mathrm{Ba}^{2+}$ solution). Considering the uncertainty in the number of ion bridges and the relatively crude estimate, this is in the right order of magnitude. In the previous study, 32 behaviour differences resulting from the type of cation were explained by difference in their size, charge, i.e. ionic potential and thus, their hydration properties. All of these factors added to the complex cation hydration process, which is not only related to the hydrated radius but also to hydration free energy, hydration enthalpy, hydration number and ion complexation, which explain the differences in the observed cation trends. ${ }^{32}$ For example, differences between the adhesion forces for $\mathrm{Mg}^{2+}$ and $\mathrm{Ca}^{2+}$, in spite of the very similar hydrated radius, can be explained by the larger number of water molecules in the $\mathrm{Mg}^{2+}$ first shell as well as its lower water exchange rate $\left(10^{-6} \mathrm{~s}\right.$ compared with $10^{-9} \mathrm{~s}$ for $\left.\mathrm{Ca}^{2+}\right) .{ }^{55}$ The characteristic strong hydration of $\mathrm{Mg}^{2+}$ decreases the probability for direct $\mathrm{Mg}^{2+}$ adsorption compared with the probability for the other ions. On the other hand, $\mathrm{Ca}^{2+}$ has been shown to have a very versatile hydration shell $(n=5.5-10.0$, depending on its concentration) and faster water exchange, which facilitates ion adsorption and thus increases the probability for ion bridge formation. ${ }^{47}$

For the asymmetric $\mathrm{CH}_{3}-\mathrm{COO}^{-}$system, the adhesion force trend $\left(\mathrm{Mg}^{2+}<\mathrm{Na}^{+}<\mathrm{Sr}^{2+}<\mathrm{Ca}^{2+}<\mathrm{Ba}^{2}\right)$ was the same as for the symmetric analogue, $\mathrm{COO}^{-}-\mathrm{COO}^{-}$. The higher adhesion force in the reference solution: $441 \pm 11 \mathrm{pN}$ in the $\mathrm{CH}_{3}-\mathrm{COO}^{-}$system compared with $229 \pm 5 \mathrm{pN}$ in the $\mathrm{COO}^{-} \mathrm{COO}^{-}$system, suggests a larger hydrophobic 
component in the surface interaction. This is consistent with the more pronounced decrease observed in $\mathrm{Mg}^{2+}(286 \pm 6 \mathrm{pN})$ because the more strongly hydrated $\mathrm{Mg}^{2+}$ ion would turn the acidic surface more water wet. ${ }^{12,56} \mathrm{In} \mathrm{Sr}^{2+}, \mathrm{Ca}^{2+}$ and $\mathrm{Ba}^{2+}$ solutions, the adhesion increased more for the $\mathrm{CH}_{3}-\mathrm{COO}^{-}$system than for the reference solution (Table 1; Figure 2).

The similarity of the ion specific response for $\mathrm{CH}_{3}-\mathrm{COO}^{-}$and $\mathrm{COO}^{-}-\mathrm{COO}^{-}$, suggests that the same mechanisms and parameters (i.e. ion size and charge, surface character and hydration properties) control the interactions. From the results observed for $\mathrm{COO}^{-}-\mathrm{COO}^{-}$, we expected cation adsorption on the charged - $\mathrm{COO}^{-}$surface but for the hydrophobic side, previous results from $\mathrm{CH}_{3}-\mathrm{CH}_{3}$ experiments ${ }^{32}$ show only hydrophobic interaction with no specific ion interaction. Hydrophobic, $-\mathrm{CH}_{3}$ functionalised surfaces are assumed to be neutral but in aqueous environments, they have been reported to develop a slight negative surface charge $\left(-0.022 \mathrm{e} / \mathrm{nm}^{2}\right)$ resulting from hydroxide, present at the water surface, toward the hydrophobic aliphatic chains. ${ }^{1}$ This slight negative surface charge would attract the net positive charge generated by the divalent cation adsorption on the - $\mathrm{COO}^{-}$surface. The adhesion forces expected for the $\mathrm{CH}_{3}-\mathrm{COO}^{-}$system are thus lower than for systems where two charged surfaces (i.e., -COO-) interact. The lower surface charge on one side weakens attraction between the surfaces, decreasing overall adhesion.

The inclusion of a -DiCOO in the interaction led to a lower adhesion than the ones recorded for ${ }^{-} \mathrm{COO}^{-}$systems. In the $\mathrm{CH}_{3}-\mathrm{DiCOO}^{-}$system, $\mathrm{Ba}^{2+}$ promoted the highest 
adhesion $(561 \pm 52 \mathrm{pN})$, followed closely by $\mathrm{Sr}^{2+}(477 \pm 83 \mathrm{pN})$ and $\mathrm{Ca}^{2+}(379 \pm 30 \mathrm{pN})$. Adhesion was lower in the reference solution $(267 \pm 23 \mathrm{pN})$ and the $\mathrm{Mg}^{2+}(222 \pm 24 \mathrm{pN})$ solutions. It is interesting that $\mathrm{Sr}^{2+}$ was responsible for higher adhesion than $\mathrm{Ca}^{2+}$ in the asymmetric $\mathrm{CH}_{3}-\mathrm{DiCOO}^{-}$system. By analogy with the $\mathrm{COO}^{-} \mathrm{COO}^{-}$system, one might expect the adhesion force series to follow the inverse cation hydrated radius trend. The strong influence of $\mathrm{Sr}^{2+}$ suggests that its size and hydration behaviour were a better fit on the -DiCOO- surface than $\mathrm{Ca}^{2+}$.

As was observed for the asymmetric $\mathrm{CH}_{3}-\mathrm{COOH}$ system, the adhesion force was also lower for the analogue $\mathrm{CH}_{3}$-DiCOO- system compared with the symmetric DiCOO-$\mathrm{DiCOO}^{-}$system, including both the interpretation of a strongly negative surface that adsorbs cations and subsequent attraction to the slightly negative, hydrophobic surface. The DiCOO--DiCOO- system produced a different adhesion force trend compared with systems where only a $-\mathrm{COO}^{-}$surface was present: $\mathrm{Na}^{+} \sim \mathrm{Mg}^{2+}<\mathrm{Ca}^{2+}<\mathrm{Ba}^{2+}<\mathrm{Sr}^{2+} . \mathrm{Sr}^{2+}$ probably formed a stronger bridge $(980 \pm 8 \mathrm{pN})$ than $\mathrm{Ba}^{2+}(910 \pm 11 \mathrm{pN})$. It is interesting that in the reference solution, adhesion for the DiCOO--DiCOO- system was $415 \pm 5 \mathrm{pN}$, which is almost double the force recorded for the same solution in the $\mathrm{COO}^{-} \mathrm{COO}^{-}$ system. From what we previously observed, higher adhesion in the reference solution is related to a hydrophobic interaction. This, in addition to the lower adhesion force compared with the $\mathrm{COO}^{-}-\mathrm{COO}^{-}$system, suggests that the - $\mathrm{DiCOO}-\mathrm{SAM}$ is not only a surface with the double density of -COO- groups. It behaves fundamentally differently. 
Each -DiCOO- molecule has two - $\mathrm{COO}^{-}$sites exposed to the solution so we expected higher charge density on the -DiCOO- surfaces, thus higher adhesion force because of more sites for ion bridging. However, the CFM results suggested lower surface charge for the -DiCOO- surface than for the -COO- surface. The lower surface charge on -DiCOOcould be explained by the structural difference between the two types of molecules. The -COO- surface presents acetate sites (Figure 3a) whereas on - $\mathrm{DiCOO}^{-}$, the sites are malonate (Figure 3b). O-O spacing and the angle they make with the molecule, i.e. the surface structure, would have an impact on the space and charge available for cation interaction.

a
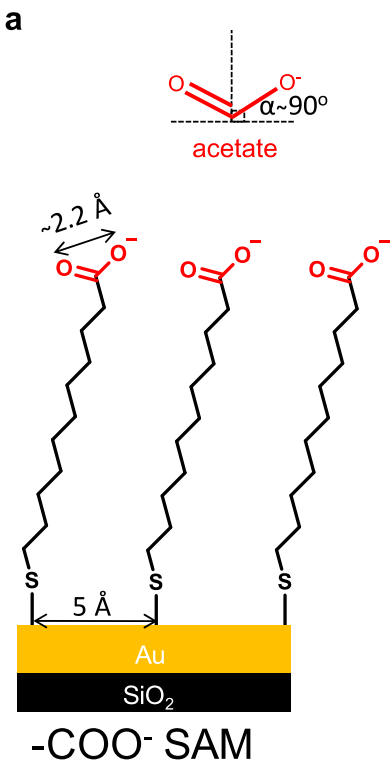

b
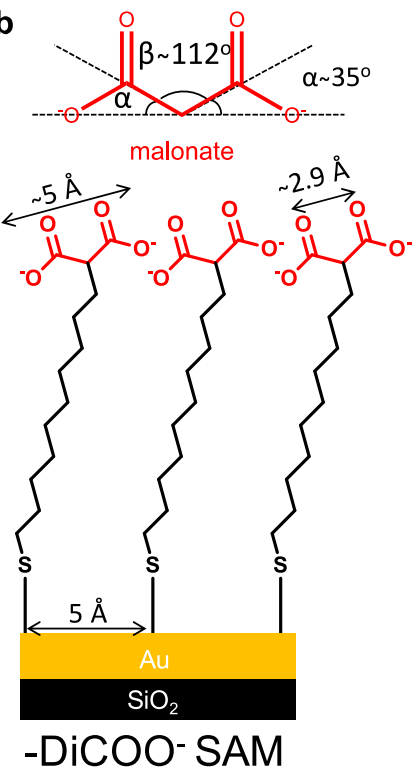

Figure 3. The structure of a) a -COO-SAM, with acetate sites and b) a -DiCOO-SAM, with malonate sites. 
Structurally, oxygen atoms in an acetate end group are usually separated at a fixed distance of $2.2 \AA$ and an angle of $122 \pm 20.57$ This value could change slightly, depending on the complex formed. ${ }^{34,57}$ In a malonate end group, the presence of methylene $(-\mathrm{CH}-)$ between the carboxylates widens the distance between the singly bonded $\mathrm{O}$ atoms $(\sim 5$ A). ${ }^{58}$ Thus, fewer molecules would be expected to cover the same area on the -DiCOOSAM than for the -COO- SAM. The reported coverage of the -COO- SAM surface is on average 4.6 molecules per $\mathrm{nm}^{2}$ which corresponds to an area per molecule of $21.6 \AA^{2}$ and a molecule spacing of $5 \AA .{ }^{59}$ The malonate group is on the limit to fit into that configuration because the distance between the carboxyls is close to $5 \AA$ and the steric repulsion between the oxygens from the carboxyls would widen the distance between the molecules.

To quantify the possible difference in surface coverage for the two SAMs, we determined overall surface composition using XPS. We first compared the signal for O$\mathrm{C}=\mathrm{O}$ carbon species $(\mathrm{BE}=289 \mathrm{eV}$ ) relative to the Au peak $(\mathrm{Au} 4 \mathrm{f}$ peak, $\mathrm{BE}=84 \mathrm{eV}$, Figure S8 in SI) from the substrate which would provide a direct measure of the functional group coverage. There are two drawbacks with this method: i) the molecules forming the SAM layer could have a different angle relative to the surface for both carboxylates, thus changing the layer thickness and the signal from the gold underneath and ii) we noticed that the - $\mathrm{DiCOO}^{-}$peak showed signs of beam damage during exposure to X-rays (Figure S9 in SI). We then used the S 2p peak (BE = 161.9 eV60 Figure S10 in SI), which represents 
the bond to $\mathrm{Au}$, relative to the Au peak intensity, to represent the abundance of adsorbed molecules in the SAM layer. Figure S10 also show the differences in intensities between unbound $\mathrm{S}$ in a SAM immediately after being extracted from the thiol solution (Figure S10a) and after being carefully washed (Figure S10b) prior CFM experiments. In this case, there was no evidence for beam damage and photoelectrons for both peaks originated from below the SAM layer, thus avoiding the problem of the layer thickness. The S/Au ratio was 0.03 for the $-\mathrm{COO}^{-}$surface and 0.04 for -DiCOO- surface (Table 2), which is the same within uncertainty, indicating that the surface coverage in terms of molecules is not significantly different for the two SAM layers. The same density for the two molecules would result in a doubling of carboxyl groups in the -DiCOO- SAM compared with the COO SAM. Nevertheless, the -DiCOO- surface was less active.

Table 2. XPS data for 11-mercaptoundecanoic acid (-COO- thiol) and 2-(10-mercaptodecyl)-malonic acid (-DiCOO- thiol). ${ }^{\text {b }}$

\begin{tabular}{|c|c|c|c|c|c|c|c|}
\hline \multicolumn{4}{|c|}{ COO- SAM surface } & \multicolumn{4}{|c|}{ DiCOO- SAM surface } \\
\hline & $\%$ & & $\%$ & & $\%$ & & $\%$ \\
\hline S 2p & 2.26 & $\begin{array}{l}\text { S-H (unbound) } \\
\text { S-Au (bound) }\end{array}$ & $\begin{array}{c}0.56 \\
1.7\end{array}$ & S 2p & 2.57 & $\begin{array}{l}\text { S-H (unbound) } \\
\text { S-Au (bound) }\end{array}$ & $\begin{array}{l}0.84 \\
1.73\end{array}$ \\
\hline Au $4 f$ & 48.7 & & & $\mathrm{Au} 4 \mathrm{f}$ & 39.7 & & \\
\hline $01 \mathrm{~s}$ & 6.62 & S-Au/Au $4 f$ & & $01 s$ & 8.95 & S-Au/Au $4 f$ & \\
\hline C 1s & 42.4 & 0.03 & & C 1s & 48.7 & 0.04 & \\
\hline
\end{tabular}

$\mathrm{b}$ B.E. refers to binding energy in $\mathrm{eV}$.

An explanation for lower surface activity on - $\mathrm{DiCOO}^{-}$surface could be interlayer interaction between the carboxyl end groups. Hydrogen bonding between neighbouring 
carboxylates has been reported to decrease the surface charge density. ${ }^{61}$ Such hydrogen bonding is more likely when the molecules in the SAM are not closely packed or when the surface to which the thiols bind, is irregular. ${ }^{62}$ Repulsion between oxygen atoms in the same malonate end group increases the separation angle between the two carbons that link the carboxyls, from 109 to $112-113^{\circ}$ (Figure 3b). This increase tilts the oxygen atoms to the side, at $\sim 35^{\circ}$ to the alkane chain, ${ }^{63-65}$ which would facilitate hydrogen bonding between neighbouring carboxyls, rather than bridging by cations, which implies longer interaction distances. The decrease in the carboxyl groups available for cation interaction reduces ion bridging availability, thus decreasing adhesion.

The spatial distribution of the carboxyls on the -DiCOO- surface could also affect interaction with the cations in solution. The - $\mathrm{DiCOO}^{-}$molecules do not stand upright (Figure 3b), which could limit the access for the hydrated cations to the negative sites. The presence of the central - $\mathrm{CH}$ - carbon, which binds the two carboxyls on the same - $\mathrm{DiCOO}^{-}$ molecule at a fixed separation distance $(2.9 \AA)$, increases local rigidity, thus limiting the possibility for an adaptive rearrangement of the carboxylate groups to the opposing surface.

We also investigated the interaction of a mixed system, COO--DiCOO- Based on the observations in the DiCOO-DiCOO system, we expected similar available surface charge on both surfaces. This agreed with the measured adhesion, which was similar to that in the COO-COO- system and higher than the DiCOO--DiCOO- system. However, the 
observed trend: $\mathrm{Na}^{+}<\mathrm{Mg}^{2+}<\mathrm{Ba}^{2+}<\mathrm{Sr}^{2+}<\mathrm{Ca}^{2+}$, in this system was not the same as for $\mathrm{COO}^{--}$ $\mathrm{COO}^{-} \mathrm{Ca}^{2+}$ bridging resulted in considerably higher adhesion than in the reference solution $\left(\Delta \mathrm{F}_{\mathrm{AD}}=1126\right)$, with lower effects from $\mathrm{Sr}^{2+}\left(\Delta \mathrm{F}_{\mathrm{AD}}=713\right), \mathrm{Ba}^{2+}\left(\Delta \mathrm{F}_{\mathrm{AD}}=528\right)$ and $\mathrm{Mg}^{2+}\left(\Delta \mathrm{F}_{\mathrm{AD}}=299\right)$. We propose that adsorption site spacing, on and between the various surfaces, determines which ions were favoured for bridging, thus which caused stronger adhesion. In magnitude, the forces for the COO--DiCOO- system were comparable with those for $\mathrm{COO}^{-} \mathrm{COO}^{-}$in the reference solution $(\sim 230 \mathrm{pN})$, with the same $\Delta \mathrm{F}_{\mathrm{AD}}$ for $\mathrm{Mg}^{2+}$ and $\mathrm{Sr}^{2+}$ (Table 1). An important difference was observed for behaviour in solutions of $\mathrm{Ca}^{2+}$ and $\mathrm{Ba}^{2}$, where adhesion forces were significantly different between the two systems. This agrees with the concept of the -DiCOO- surface having lower available surface charge, thus lower affinity for bridging and lower adhesion.

\section{Ion selectivity}

Although the structural and surface charge density differences for the various monolayers could explain most of the results, the dependence of the specific ion effects to the surfaces involved in the interaction is still not completely understood. Ion bridge theory is compatible with the adhesion force trend observed for the $\mathrm{COO}^{-} \mathrm{COO}^{-}$system $\left(\mathrm{Na}^{+} \sim \mathrm{Mg}^{2+}<\mathrm{Sr}^{2+}<\mathrm{Ca}^{2+}<\mathrm{Ba}^{2+}\right)$ where the reduction of the ion bridge force can be linked to the increase of the hydrated radius of the cation. The different trend observed in systems with the -DiCOO- surfaces, where $\mathrm{Sr}^{2+}$ and $\mathrm{Ca}^{2+}$ produced higher adhesion than 
the less hydrated $\mathrm{Ba}^{2+}$, suggest that in this case, other parameters affect ion bridge formation.

For an ion bridge to form, an interaction of a charged surface with an ion is required. Thus, understanding ion complexation with the exposed groups of the studied SAM surfaces (acetate and malonate) gives us valuable information about the nature of the ion bridging. Spectroscopic characterisation ${ }^{34}$ shows that the acetate group, exposed on the -COO- surface, forms four common complexation structures: monodentate (Figure 4a) where the metal ion interacts with only one oxygen atom of a -COO- group; bidentate (Figure 4b), where the metal interacts equally with two oxygen atoms of a - $\mathrm{COO}^{-}$group; bridging (Figure 4c), where each of the oxygen atoms of the same -COO- interact with a metal; and pseudobridging (Figure 4d), where one oxygen of a -COO-group interacts with a metal and the other interacts with water.

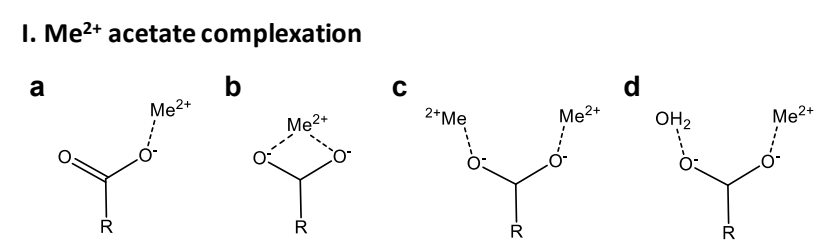

II. $\mathrm{Me}^{2+}$ malonate complexation

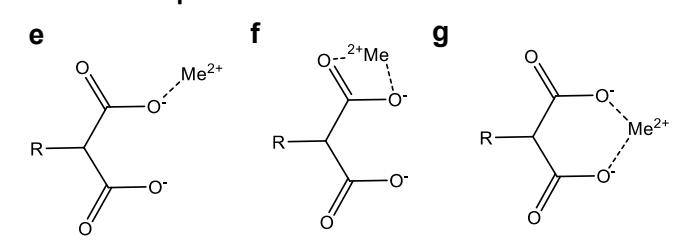

Figure 4. Expected structures for: I. metal-acetate complexation: a) unidentate, b) bidentate, c) bridging, and d) pseudobridging. II. metal-malonate complexation: e) 
unidentate, $\mathrm{f}$ ) bidentate and $\mathrm{g}$ ) malonate chelation or chelation bidentate (modified from Deerfield et al. $1991^{65}$ and Nara et al. 201334).

Malonate complexes, expected to form on -DiCOO- surfaces, are usually unidentate and bidentate (Figure $4 \mathrm{f}$ and $\mathrm{g}$ ) and a characteristic structure called malonate chelation or bidentate chelation (Figure 4h), where the metal ion interacts with an oxygen from each of the two carboxylates of the malonate group. ${ }^{65}$ Malonate chelation is of special interest in our case because it is the preferred mode of interaction of the malonate group with alkali earth metals. ${ }^{66}$ Particularly with $\mathrm{Sr}^{2+}$, malonate usually coordinates only by chelation complexes in an structure where three malonate groups form a complex in which six oxygens are linked through one $\mathrm{Sr}^{2+}$ ion (Figure 4a). ${ }^{63,67}$ This complexation structure is the most thermally stable among the malonate complexes with metal earth cations as is observed by comparing the decomposition temperature of the malonate complexes with the cations $\left(\mathrm{Mg}^{2+}, 310{ }^{\circ} \mathrm{C}, \mathrm{Ca}^{2+}, 325^{\circ} \mathrm{C}, \mathrm{Sr}^{2+}, 335^{\circ} \mathrm{C}\right.$ and $\left.\mathrm{Ba}^{2+}, 161{ }^{\circ} \mathrm{C}\right) .68,69$ The higher stability of a strontium malonate complex usually correlates with higher affinity of $\mathrm{Sr}^{2+}$ for the malonate structure i.e., the distance and angle between the chelating sites, which allows a compact complexation only by chelating interactions.

Ion bridging requires ion complexation by the two opposing surfaces so the higher adhesion forces between the DiCOO--DiCOO- system in $\mathrm{Sr}^{2+}$ solution could be related with the stability of the $\mathrm{Sr}^{2+}$ malonate complex. This would directly affect ion bridge formation and thus the adhesion force. It is expected that stronger chelation would lead 
to higher adhesion force because in an optimal complex, a more compact structure would increase the stability of the aggregation. This implies a reduction in the interaction distances between the ligands from the two interacting surfaces and the ion, thus higher adhesion forces. The possibility of $\mathrm{Sr}^{2+}$ complex formation between the two -DiCOOsurfaces, as is suggested in Figure $5 \mathrm{a}$, is consistent with the observed stability of $\mathrm{Sr}^{2+}$ malonate complexes, the preference of -DiCOO- surfaces for $\mathrm{Sr}^{2+}$ as well as the higher adhesion force when -DiCOO- surfaces interact in $\mathrm{Sr}^{2+}$ solution.
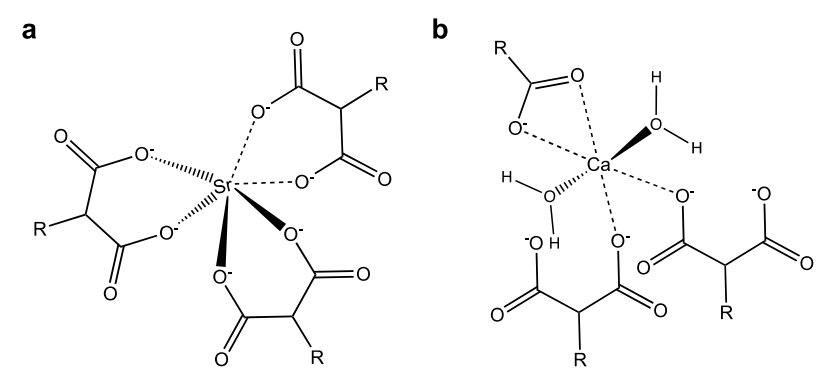

Figure 5. Proposed complexation structures for: a) strontium and b) calcium ion in the interaction between SAM carboxylates.

Optimal complexation of $\mathrm{Ca}^{2+}$ during ion bridge formation, could also explain the high adhesion measured in the $\mathrm{Ca}^{2+}$ solution for the COO--DiCOO- system. Increased adhesion caused by $\mathrm{Ca}^{2+}$ could result from formation of a stable complex of $\mathrm{Ca}^{2+}$. $\mathrm{Ca}^{2+}$ usually coordinates $^{63}$ with six oxygens, two from water, two from an acetate in a bidentate mode (Figure 5b) and two others, each from different carboxylate groups in a unidentate form. The particular distribution of oxygen in the $\mathrm{COO}^{-} \mathrm{DiCOO}^{-}$system could allow structured interaction, were bidentate complexing comes from the acetate of the $\mathrm{COO}^{-}$on the tip 
and unidentate complexing with oxygen from two different malonate groups on the surface, as is shown in Figure $5 b$. This hypothesis is supported by the evidence that the lowest interaction energy, thus the more energetically stable carboxyl-Ca ${ }^{2+}$ complex, is reached when three carboxyls interact with cation. ${ }^{65,70}$ Such an optimal distribution of binding enhances the interaction of $\mathrm{Ca}^{2+}$ ions with interacting surfaces, inducing higher adhesion forces. ${ }^{57}$

\section{CONCLUSIONS}

Using AFM in CFM mode, we measured the interaction between - $\mathrm{CH}_{3},-\mathrm{COO}^{-}$and DiCOO- SAM surfaces during exposure to $0.5 \mathrm{M} \mathrm{NaCl}$ and in solutions where chloride salts of $\mathrm{Mg}^{2+}, \mathrm{Ca}^{2+}, \mathrm{Sr}^{2+}$ and $\mathrm{Ba}^{2+}$ had been added, to produce concentrations of $0.012 \mathrm{M} \mathrm{Me}^{2+}$.

The effect of the reference solution on the adhesion force was mainly a result of direct surface interactions, through van der Waals and hydrophobic forces, which explains the lower forces recorded in systems that are more hydrophilic, i.e. $\mathrm{COO}^{-} \mathrm{COO}^{-}$and higher forces for the more hydrophobic systems.

For divalent cation solutions, we demonstrated consistency between ion bridge theory and the data collected using CFM for systems with charged surfaces (i.e., -COO- and $\left.\mathrm{DiCOO}^{-}\right)$. For systems with only -COO- surfaces, the adhesion force series followed the inverse cation hydrated radius trend $\left(\mathrm{Na}^{+} \sim \mathrm{Mg}^{2+}<\mathrm{Sr}^{2+}<\mathrm{Ca}^{2+}<\mathrm{Ba}^{2+}\right)$, with higher $\mathrm{F}_{\mathrm{AD}}$ for the symmetric system, $\mathrm{COO}^{-} \mathrm{COO}^{-}$, than for the asymmetric system, $\mathrm{CH}_{3}-\mathrm{COO}^{-}$. The 
hydrophobic surface decreased the possibility for stronger cation bridging with the charged -COO- surface, resulting in lower adhesion.

$\mathrm{F}_{\mathrm{AD}}$ was consistently lower in the asymmetric $\mathrm{CH}_{3}{ }^{-} \mathrm{DiCOO}-$ system than in the symmetric DiCOO-DiCOO- system. Compared to systems where - $\mathrm{COO}^{-}$was present, the presence of -DiCOO- led to lower adhesion force. This probably resulted from the structure of the malonate end groups that are exposed on the -DiCOO- SAM. This would affect surface charge density and the shape of the adsorption sites. The characteristic structure of the DiCOO- surface was responsible for different adhesion strength trends: adhesion was

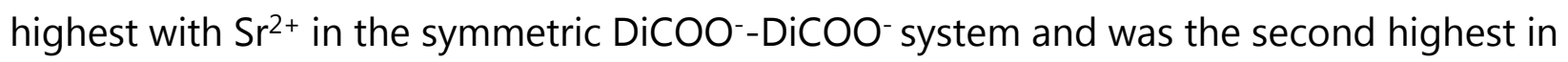
the asymmetric $\mathrm{CH}_{3}-\mathrm{DiCOO}^{-}$system after $\mathrm{Ba}^{2+}$. In the mixed system, $\mathrm{COO}^{--} \mathrm{DiCOO}^{-}, \mathrm{Ca}^{2+}$ promoted the highest force. The specific responses of $\mathrm{Sr}^{2+}$ and $\mathrm{Ca}^{2+}$ were analysed from the light of reported malonate complexation modes. Comparison of adhesion force from previous studies suggested that the strong response of the -DiCOO- surface in solutions of $\mathrm{Sr}^{2+}$ resulted from a chelation bidentate interaction, whereas response in $\mathrm{Ca}^{2+}$ solutions could be attributed to an association of the malonate group via alpha mode.

\section{ASSOCIATED CONTENT}

\section{Supporting Information}

The following file is available free of charge: information about spectroscopic characterisation (NMR, HR-MS spectra) of Molecules 1 and 2, force curves, force maps 
and force map distributions for the systems used and XPS spectra from - $\mathrm{COO}^{-}$and DiCOO- SAMs.

\section{AUTHOR INFORMATION}

Corresponding Author

trca@topsoe.com

\section{Author Contributions}

The manuscript was written with contributions from all authors. All authors have approved the final version.

\section{Funding Sources}

This study was made during the project called: "Nano-Heal: Nano-tailoring organomineral materials: Controlling strength and healing with organic molecules in mineral interfaces" under the grant agreement No. 642976 MSCA-ITN-2014-ETN: Maria Skłodowska- Curie Innovative Training Network. Some of the funding was provided by the NanoGeoScience Research Group.

\section{ACKNOWLEDGMENTS}

We are grateful to Knud Dideriksen and Zilong Liu for insightful suggestions and discussion.I would like to thank to Marcel Ceccato for his helpful ideas for improving the synthetic route. We 
also thank the members of the Nano-Heal Network, especially Teresa Liberto and Joanna Dziadkowiec for help in the laboratory and for discussion.

\section{REFERENCES}

(1) Schwierz, N.; Horinek, D.; Netz, R. R. Anionic and Cationic Hofmeister Effects on Hydrophobic and Hydrophilic Surfaces. Langmuir 2013, 29, 2602-2614.

(2) Boström, M.; Kunz, W.; Ninham, B. W. Hofmeister Effects in Surface Tension of Aqueous Electrolyte Solution. Langmuir 2005, 21, 2619-2623.

(3) Hassenkam, T.; Skovbjerg, L. L.; Stipp, S. L. S. Probing the Intrinsically Oil-Wet Surfaces of Pores in North Sea Chalk at Subpore Resolution. Proc. Natl. Acad. Sci. U. S. A. 2009, 106, 6071-6076.

(4) Hilner, E.; Andersson, M. P.; Hassenkam, T.; Matthiesen, J.; Salino, P. A.; Stipp, S. L. The Effect of Ionic Strength on Oil Adhesion in Sandstone--the Search for the Low Salinity Mechanism. Sci Rep 2015, 5, 9933.

(5) Valleau, J. P.; Ivkov, R.; Torrie, G. M. Colloid Stability: The Forces between Charged Surfaces in an Electrolyte. J. Chem. Phys. 1991, 95, 520-532.

(6) López-León, T.; Jódar-Reyes, A. B.; Ortega-Vinuesa, J. L.; Bastos-González, D. Hofmeister Effects on the Colloidal Stability of an IgG-Coated Polystyrene Latex. J. Colloid Interface Sci. 2005, 284, 139-148.

(7) Liang, Y.; Hilal, N.; Langston, P.; Starov, V. Interaction Forces between Colloidal Particles in Liquid: Theory and Experiment. Adv. Colloid Interface Sci. 2007, 134-135, 151-166.

(8) Babu, C. S.; Dudev, T.; Casareno, R.; Cowan, J. A.; Lim, C. A Combined Experimental and Theoretical Study of Divalent Metal Ion Selectivity and Function in Proteins: Application to E. Coli Ribonuclease H1. J. Am. Chem. Soc. 2003, 125, 9318-9328.

(9) Pashley, R. M.; Israelachvili, J. N. Dlvo and Hydration Forces between Mica Surfaces in $\mathrm{Mg} 2+, \mathrm{Ca} 2+, \mathrm{Sr} 2+$, and Ba2+ Chloride Solutions. J. Colloid Interface Sci. 1984, 97, 446-455.

(10) Liu, X.; Yan, W.; Stenby, E. H.; Thormann, E. Release of Crude Oil from Silica and Calcium Carbonate Surfaces: On the Alternation of Surface and Molecular Forces by High- and Low-Salinity Aqueous Salt Solutions. Energy and Fuels 2016, 30, 39863993. 
(11) Liu, X.; Feilberg, K. L.; Yan, W.; Stenby, E. H.; Thormann, E. Electrical Double-Layer and Ion Bridging Forces between Symmetric and Asymmetric Charged Surfaces in the Presence of Mono- and Divalent Ions. Langmuir 2017, 33, 4426-4434.

(12) Andersson, M. P.; Dideriksen, K.; Sakuma, H.; Stipp, S. L. S. Modelling How Incorporation of Divalent Cations Affects Calcite Wettability-Implications for Biomineralisation and Oil Recovery. Sci. Rep. 2016.

(13) Juhl, K. M. S.; Bovet, N.; Hassenkam, T.; Dideriksen, K.; Pedersen, C. S.; Jensen, C. M.; Okhrimenko, D. V.; Stipp, S. L. S. Change in Organic Molecule Adhesion on $\alpha-$ Alumina (Sapphire) with Change in $\mathrm{NaCl}$ and $\mathrm{CaCl} 2$ Solution Salinity. Langmuir 2014.

(14) Horinek, D.; Netz, R. R. Specific Ion Adsorption at Hydrophobic Solid Surfaces. Phys. Rev. Lett. 2007, 99, 226104.

(15) Schweiss, R.; Welzel, P. B.; Werner, C.; Knoll, W. Dissociation of Surface Functional Groups and Preferential Adsorption of Ions on Self-Assembled Monolayers Assessed by Streaming Potential and Streaming Current Measurements. Langmuir 2001, 17, 4304-4311.

(16) Juhl, K. M. S.; Pedersen, C. S.; Bovet, N.; Dalby, K. N.; Hassenkam, T.; Andersson, M. P.; Okhrimenko, D.; Stipp, S. L. S. Adhesion of Alkane as a Functional Group on Muscovite and Quartz: Dependence on PH and Contact Time. Langmuir 2014.

(17) Stipp, S. L. S.; Konnerup-Madsen, J.; Franzreb, K.; Kulik, A.; Mathieu, H. J. Spontaneous Movement of Ions through Calcite at Standard Temperature and Pressure. Nature 1998, 396, 356.

(18) Israelachvili, J. N.; Adams, G. E. Measurement of Forces between Two Mica Surfaces in Aqueous Electrolyte Solutions in the Range 0-100 Nm. J. Chem. Soc. Faraday Trans. 1 Phys. Chem. Condens. Phases 1978, 74, 975-1001.

(19) Pashley, R. M. DLVO and Hydration Forces between Mica Surfaces in $\mathrm{Li}+, \mathrm{Na}+, \mathrm{K}+$, and Cs+ Electrolyte Solutions: A Correlation of Double-Layer and Hydration Forces with Surface Cation Exchange Properties. J. Colloid Interface Sci. 1981, 83, 531-546.

(20) Chapel, J. P. Electrolyte Species Dependent Hydration Forces between Silica Surfaces. Langmuir 1994, 10, 4237-4243.

(21) Dziadkowiec, J.; Javadi, S.; Bratvold, J. E.; Nilsen, O.; Røyne, A. Surface Forces Apparatus Measurements of Interactions between Rough and Reactive Calcite Surfaces. Langmuir 2018, 34, 7248-7263. 
(22) Hillier, A. C.; Kim, S.; Bard, A. J. Measurement of Double-Layer Forces at the Electrode/Electrolyte Interface Using the Atomic Force Microscope: Potential and Anion Dependent Interactions. J. Phys. Chem. 1996, 100, 18808-18817.

(23) Dishon, M.; Zohar, O.; Sivan, U. From Repulsion to Attraction and Back to Repulsion: The Effect of $\mathrm{NaCl}, \mathrm{KCl}$, and $\mathrm{CsCl}$ on the Force between Silica Surfaces in Aqueous Solution. Langmuir 2009, 25, 2831-2836.

(24) Rimmen, M.; Matthiesen, J.; Bovet, N.; Hassenkam, T.; Pedersen, C. S.; Stipp, S. L. S. Interactions of $\mathrm{Na}+, \mathrm{K}+, \mathrm{Mg} 2+$, and $\mathrm{Ca} 2+$ with Benzene Self-Assembled Monolayers. Langmuir 2014, 30, 9115-9122.

(25) Skovbjerg, L. L.; Hassenkam, T.; Makovicky, E.; Hem, C. P.; Yang, M.; Bovet, N.; Stipp, S. L. S. Nano Sized Clay Detected on Chalk Particle Surfaces. Geochim. Cosmochim. Acta 2012, 99, 57-70.

(26) Hassenkam, T.; Mitchell, A. C.; Pedersen, C. S.; Skovbjerg, L. L.; Bovet, N.; Stipp, S. L. S. The Low Salinity Effect Observed on Sandstone Model Surfaces. Colloids Surfaces A Physicochem. Eng. Asp. 2012, 403, 79-86.

(27) Lorenz, B.; Ceccato, M.; Andersson, M. P.; Dobberschütz, S.; Rodriguez-Blanco, J. D.; Dalby, K. N.; Hassenkam, T.; Stipp, S. L. S. Salinity-Dependent Adhesion Response Properties of Aluminosilicate (K-Feldspar) Surfaces. Energy \& Fuels 2017, acs.energyfuels.6b02969.

(28) Noy, A.; Vezenov, D. V.; Lieber, C. M. Chemical Force Microscopy. Annu. Rev. Mater. Sci. 1997, 27, 381-421.

(29) Drelich, J.; Mittal, K. L. Atomic Force Microscopy in Adhesion Studies, Taylor \& F.; Taylor \& Francis Group, Ed.; CRC Press: Leiden-Boston, 2005.

(30) Israelachvili, J. N. Intermolecular and Surface Forces, 3rd ed.; Elsevier B.V.: Santa Barbara, California, 2011.

(31) Kokkoli, E.; Zukoski, C. F. Interactions between Hydrophobic Self-Assembled Monolayers . Effect of Salt and the Chemical Potential of Water on Adhesion. Langmuir 1998, 7463, 1189-1195.

(32) Rios-Carvajal, T.; Pedersen, N. R.; Bovet, N.; Stipp, S. L. S.; Hassenkam, T. Specific Ion Effects on the Interaction of Hydrophobic and Hydrophilic Self Assembled Monolayers. Langmuir 2018, 10.

(33) Deerfield, D. W.; Nicholas, H. B.; Hiskey, R. G.; Pedersen, L. G. Salt or Ion Bridges in Biological System: A Study Employing Quantum and Molecular Mechanics. Proteins 
Struct. Funct. Bioinforma. 1989, 6, 168-192.

(34) Nara, M.; Morii, H.; Tanokura, M. Coordination to Divalent Cations by CalciumBinding Proteins Studied by FTIR Spectroscopy. Biochim. Biophys. Acta - Biomembr. 2013, 1828, 2319-2327.

(35) Schwierz, N.; Horinek, D.; Netz, R. R. Specific Ion Binding to Carboxylic Surface Groups and the Ph Dependence of the Hofmeister Series. Langmuir 2015, 31, 215225.

(36) Dobberschutz, S.; Rimmen, M.; Hassenkam, T.; Andersson, M. P.; Stipp, S. Specific Ion Effects on the Hydrophobic Interaction of Benzene Self-Assembled Monolayers. Phys. Chem. Chem. Phys. 2015, 17, 21432.

(37) Gilbert, P. U. P. A. The Organic-Mineral Interface in Biominerals. Rev. Mineral. Geochemistry 2005, 59, 157-185.

(38) Love, J. C.; Estroff, L. a.; Kriebel, J. K.; Nuzzo, R. G.; Whitesides, G. M. Self-Assembled Monolayers of Thiolates on Metals as a Form of Nanotechnology. Chem. Rev. 2005, 105, 1103-1169.

(39) Simard, J. M.; Szymanski, B.; Rotello, V. M. Reversible Regulation of Chymotrypsin Activity Using Negatively Charged Gold Nanoparticles Featuring Malonic Acid Termini. Med Chem 2005, 1, 153-157.

(40) Wei, Z.; Li, T.; Jennum, K.; Santella, M.; Bovet, N.; Hu, W.; Nielsen, M. B.; Bjørnholm, T.; Solomon, G. C.; Laursen, B. W.; et al. Molecular Junctions Based on SAMs of Cruciform Oligo(Phenylene Ethynylene)S. Langmuir 2012, 28, 4016-4023.

(41) Epoxy Technology. EPO-TEK 353ND Data Sheet; Billerica, MA, 2014.

(42) Li; Estroff, L. A. Hydrogels Coupled with Self-Assembled Monolayers: An in Vitro Matrix To Study Calcite Biomineralization. J. Am. Chem. Soc. 2007, 129, 5480-5483.

(43) Millero, F. J.; Feistel, R.; Wright, D. G.; McDougall, T. J. The Composition of Standard Seawater and the Definition of the Reference-Composition Salinity Scale. Deep Sea Res. Part I Oceanogr. Res. Pap. 2008, 55, 50-72.

(44) Pedersen, N. R.; Hassenkam, T.; Ceccato, M.; Dalby, K. N.; Mogensen, K.; Stipp, S. L. S. The Low Salinity Effect at Pore Scale: Probing Wettability Changes in Middle East Limestone. Energy \& Fuels 2016, 30, 3768-3775.

(45) Røyne, A.; Dalby, K. N.; Hassenkam, T. Repulsive Hydration Forces between Calcite Surfaces and Their Effect on the Brittle Strength of Calcite-Bearing Rocks. Geophys. Res. Lett. 2015, 42, 4786-4794. 
(46) Fears, K. P.; Creager, S. E.; Latour, R. A. Determination of the Surface PK of Carboxylic- and Amine-Terminated Alkanethiols Using Surface Plasmon Resonance Spectroscopy. Langmuir 2008, 24, 837-843.

(47) Marcus, Y. Ionic Radii in Aqueous Solutions. J. Solution Chem. 1983.

(48) Conway, B. E. Ion Hydration Co-Sphere Interactions in the Double-Layer and Ionic Solutions. J. Electroanal. Chem. 1981.

(49) Marcus, Y. A Simple Empirical Model Describing the Thermodynamics of Hydration of Ions of Widely Varying Charges, Sizes, and Shapes. Biophys. Chem. 1994, 51, 111127.

(50) Kokkoli, E.; Zukoski, C. Interaction Forces between Hydrophobic and Hydrophilic Self-Assembled Monolayers. J. Colloid Interface Sci. 2000, 230, 176-180.

(51) Derjaguin, B. V; Muller, V. M.; Toporov, Y. U. P. Effect of Contact Deformation on the Adhesion of Particles. J. Colloid Interface Sci. 1975, 52, 105-108.

(52) Johnson, K. L.; Kendall, K.; Roberts, A. D. Surface Energy and the Contact of Elastic Solids. Proc. R. Soc. London. A. Math. Phys. Sci. 1971, 324, 301 LP - 313.

(53) Olympus Corporation. Olympus biolevers BL-RC150VB.

(54) Schreiber, F. Structure and Growth of Self-Assembling Monolayers. Prog. Surf. Sci. 2000, 65, 151-257.

(55) Fraústo da Silva, J. J. R.; Williams, R. J. P. The Biological Chemistry of the Elements: The Inorganic Chemistry of Life, Second Edi.; Clarendon Press, Oxford., 1992.

(56) Andersson, M. P.; Stipp, S. L. S. Predicting Hydration Energies for Multivalent Ions. J. Comput. Chem. 2014, 35, 2070-2075.

(57) Einspahr, H.; Bugg, C. E. The Geometry of Calcium Carboxylate Interactions in Crystalline Complexes. Acta Crystallogr. Sect. B Struct. Crystallogr. Cryst. Chem. 1981, 37, 1044-1052.

(58) Salinas-Nolasco, M. F.; Méndez-Vivar, J.; Lara, V. H.; Bosch, P. Passivation of the Calcite Surface with Malonate Ion. J. Colloid Interface Sci. 2004, 274, 16-24.

(59) Hinterwirth, H.; Kappel, S.; Waitz, T.; Prohaska, T.; Lindner, W. Quantifying Thiol Ligand Density of Self-Assembled Monolayers on Gold Nanoparticles by Inductively Coupled Plasma À Mass Spectrometry. 2013, No. 2, 1129-1136.

(60) Castner, D. G.; Hinds, K.; Grainger, D. W. X-Ray Photoelectron Spectroscopy Sulfur 
$2 p$ Study of Organic Thiol and Disulfide Binding Interactions with Gold Surfaces. Langmuir 1996, 12, 5083-5086.

(61) Jacquelín, D. K.; Pérez, M. A.; Euti, E. M.; Arisnabarreta, N.; Cometto, F. P.; ParedesOlivera, P.; Patrito, E. M. A PH-Sensitive Supramolecular Switch Based on Mixed Carboxylic Acid Terminated Self-Assembled Monolayers on Au(111). Langmuir 2016, 32, 947-953.

(62) Carot, M. L.; Macagno, V. A.; Paredes-Olivera, P.; Patrito, E. M. Structure of Mixed Carboxylic Acid Terminated Self-Assembled Monolayers: Experimental and Theoretical Investigation. J. Phys. Chem. C 2007, 111, 4294-4304.

(63) Briggman, B.; Oskarsson, A. The Crystal Structures of Calcium Malonate Dihydrate and Strontium Malonate. Acta Crystallogr. Sect. B 1977, 33, 1900-1906.

(64) Deerfield, D. W.; Pedersen, L. G. Enol and Deprotonated Forms of Acetic and Malonic Acid. J. Mol. Struct. 1996, 368, 163-171.

(65) Deerfieid, D. W.; Fox, D. J.; Head-Gordon, M.; Hiskey, R. G.; Pedersen, L. G. Interaction of Calcium and Magnesium Ions with Malonate and the Role of the Waters of Hydration: A Quantum Mechanical Study. J. Am. Chem. Soc. 1991, 113, 1892-1899.

(66) Mathew, V.; Joseph, J.; Jacob, S.; Abraham, K. E. Spectroscopic Characterization of Gel Grown Strontium Malonate Crystals. Indian J. Pure Appl. Phys. 2011, 49, 21-24.

(67) Mehandzhiyski, A. Y.; Riccardi, E.; van Erp, T. S.; Trinh, T. T.; Grimes, B. A. Ab Initio Molecular Dynamics Study on the Interactions between Carboxylate Ions and Metal Ions in Water. J. Phys. Chem. B 2015, 119, 10710-10719.

(68) Yang, Y.; Jiang, G.; Li, Y. Z.; Bai, J.; Pan, Y.; You, X. Z. Synthesis, Structures and Properties of Alkaline Earth Metal Benzene-1,4-Dioxylacetates with ThreeDimensional Hybrid Networks. Inorganica Chim. Acta 2006, 359, 3257-3263.

(69) Randhawa, B. S.; K., S.; Bassi, P. S. Thermal Decomposition of Strontium and Barium Malonates. J. Therm. Anal. Calorim. 1999, 55, 789-796.

(70) Mehandzhiyski, A. Y.; Riccardi, E.; Van Erp, T. S.; Koch, H.; Åstrand, P.-O.; Trinh, T. T.; Grimes, B. A. Density Functional Theory Study on the Interactions of Metal Ions with Long Chain Deprotonated Carboxylic Acids. J. Phys. Chem. A 2015. 


\section{Graphical Abstract}

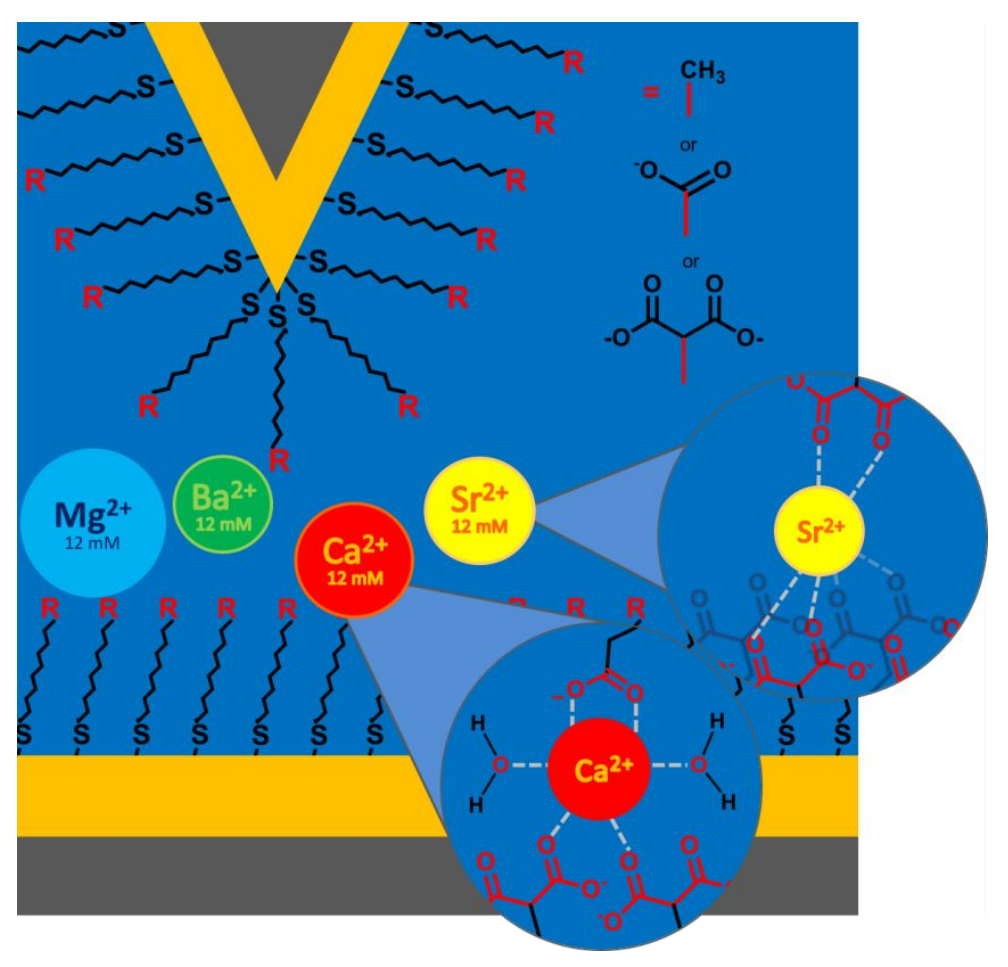

